\title{
PENATAAN ANCAMAN EKONOMI SEBAGAI BAGIAN DARI KEADAAN BAHAYA DI INDONESIA
}

\author{
Agus Adhari \\ Faculty of Social Science, Universitas Pembangunan Panca Budi \\ agusadhari@dosen.pancabudi.ac.id/adharyagus@gmail.com
}

Submitted: 2020-10-07 ;Reviewed: 2020-10-09; Accepted: 2020-11-20

\begin{abstract}
This article aims to analyze economic threats in times of emergency. Threats in the modern era consist of many types, and most of it dominated by nonmilitary threats such as disasters and social conflicts. However, apart from these two threats, economic threats also have the same effect on national security. The Indonesian government has been responded to economic threats differently since 1998 when it faced an economic crisis, then when it faced the threat of an economic recession due to the impact of the Covid-19 Pandemic. The difference in ways of responding to economic threats is because Indonesia does not regulate economic threats as threats of state of emergency, so policies to respond to economic threats are limited by rules that cannot be violated. Therefore, this article will discuss the arrangement of economic threats in times of emergency. As a result, by regulating an economic threat as part of a state of emergency, the government has the power to shape economic policy by deviating from the provisions that apply under normal conditions. The economic emergency arrangement is carried out by regulating economic threats as part of a state of emergency through the law, then also regulates the scope of the President's powers, the organ of exercising power, time limits, and forms of responsibility.
\end{abstract}

Keyword: Economic Emergency; Nonmilitary Threat; state of emergency.

\section{PENDAHULUAN}

Pada awal negara-negara modern berdiri, ancaman keadaan bahaya selalu dikaitkan dengan ancaman yang bersifat militer di mana perang antar negara dalam memperebutkan wilayah dan pengaruh sering terjadi, sehingga paradigma keadaan bahaya yang digunakan 
Dialogia luridica: Jurnal Hukum Bisnis dan Investasi

Volume 12 Nomor 1, November 2020

adalah paradigma ancaman militer. Hal ini sebagaimana dijelaskan oleh John Armitage, sebagaimana berikut:

"The orthodox modern State of Emergency was a situation, declared by the state, in which the strategies and tactics of the military were employed legally, typically because of a number of occurrences of civil disorder such as terrorism, the methodical use of carnage and coercion to attain political aims". ${ }^{1}$

Lebih lanjut, Stephen Morton berpendapat, bahwa selama keadaan bahaya terjadi "executive power is used to suspend the normal rule of law, and the power is transferred to the police or military". ${ }^{2}$ Namun, sejak berakhirnya perang dingin ancaman keadaan bahaya tidak hanya berkaitan dengan ancaman militer melainkan juga ancaman nonmiliter. Pendapat ini dipertegas oleh Richard H. Ullman:

"We are, of course, accustomed to thinking of national security in terms of military threats arising from beyond the borders of one's own country. But that emphasis is doubly misleading. It draws attention away from the nonmilitary threats that promise to undermine the stability of many nations during the years ahead. And it presupposes that threats arising from outside a state are somehow more dangerous to its security than threats that arise within it". ${ }^{3}$

Ancaman militer dan ancaman nonmiliter memiliki perbedaan yang jelas, di mana ancaman militer selalu berkaitan dengan serangan militer dari pihak asing yang mengancam kedaulatan negara, sedangkan ancaman nonmiliter merupakan ancaman yang berasal dari internal negara dan memiliki karakteristik yang mengancam keamanan nasional. Ajey Lele berpendapat mengenai ancaman nonmiliter sebagai berikut:

"The nonmilitary threats could be defined as those activities in which nonmilitary means are predominantly employed that threaten the security of the nation-state. General nonmilitary threats include emergencies other than armed conflict such as terrorist activities, illegal weapons transfer, uncontrolled migration or massive refugee flow, religious or ethnic extremism and rivalries, international organized crime, social unrest, and a number of other activities that may lead to armed conflict if unresolved". ${ }^{4}$

Indonesia sendiri sejak awal kemerdekaan termasuk negara yang menggabungkan ancaman militer dan ancaman nonmiliter dalam keadaan bahaya. Pengaturan tersebut

\footnotetext{
${ }^{1}$ John Armitage, "State of Emergency: An Introduction", Journal Theory, Culture \& Society, Volume 19 No. 4, 2001, hlm. 27-38.

${ }^{2}$ Stephen Morton, States of Emergency: Colonialism, Literature and Law, Liverpool: Liverpool University Press, 2013, hlm. 1.

${ }^{3}$ Richard H. Ullman, "Redefining Security", Journal of International Security, Volume 8, No. 1, 1983, hlm. 129-153.

${ }^{4}$ Ajey Lele, "Natural disasters: A nonmilitary threat to national security" dalam Chatterji, M. and Jain, B.M.(ed), Conflict and Peace in South Asia: Contributions to Conflict Management, Peace Economics and Development, Vol. 5, Bingley: Emerald Group Publishing Limited, 2008, hlm. 74.
} 
dimulai dengan dibentuknya UU 6/1946 yang mengatur perang, kerusuhan dan bencana alam sebagai bagian keadaan bahaya. Pengaturan tersebut terus dilakukan hingga Perppu 23/1959 dibentuk dan berlaku hingga sekarang. Namun, setelah era reformasi, pemisahan mengenai ancaman militer dan ancaman nonmiliter dalam keadaan bahaya dilakukan melalui UU 24/2007 yang mengatur masalah bencana, kemudian melalui UU 7/2012 mengatur masalah konflik sosial dan melalui UU 6/2018 mengatur masalah ancaman penyakit. Ketiga undang-undang di atas mengatur ancaman bencana, konflik dan penyakit secara berbeda dari yang diatur dalam Perppu 23/1959, baik mengenai kekuasaan, batas waktu hingga organ pelaksana kekuasaannya.

Dari banyaknya ancaman nonmiliter yang diatur, terdapat satu ancaman yang belum diatur sebagai bagian dari keadaan bahaya kendati memiliki dampak yang sama terhadap keamanan negara. Ancaman tersebut terkait masalah ekonomi yang lahir karena dampak sanksi ekonomi maupun yang lahir dari faktor internal seperti krisis ekonomi, resesi hingga depresi ekonomi. Beberapa ancaman ekonomi tersebut pernah dialami Indonesia seperti krisis ekonomi Tahun 1998, dampak krisis global Tahun 2008 hingga ancaman resesi ekonomi Tahun 2020 sebagai dampak penyebaran Covid-19.

Pemerintah Indonesia kemudian merespon ketiga ancaman tersebut secara berbedabeda seperti saat mengatasi krisis ekonomi 1998, pemerintah membentuk kebijakan yang justru memperburuk kondisi ekonomi. Hal Hill mencatat tiga kebijakan yang dilakukan pemerintah saat menghadapi krisis ekonomi 1998 merupakan suatu kesalahan yang memperburuk kondisi:

"The first major policy mistake was the sudden closure of 16 banks on 1 November 1997...The second set of problems related to the growing perception that President Soeharto was intent on protecting his family's commercial interests at all costs, a sentiment that quickly snowballed into a general loss of confidence in the regime's economic management credentials...The government had just signed an impossibly ambitious agreement with the IMF". 5

Kemudian, saat merespon dampak krisis global 2008, pemerintah membentuk tiga Perppu yaitu Perppu 2/2008 tentang perubahan UU Bank Indonesia, Perppu 3/2008 tentang Lembaga Penjamin Simpanan (LPS) dan Perppu 4/2008 tentang Jaring Pengaman Sistem Keuangan (JPSK). Kemudian saat merespon ancaman krisis ekonomi, pemerintah kembali membentuk Perppu 1/2020 dengan tujuan pemulihan ekonomi nasional.

Dominasi penggunaan Perppu sebagai instrumen merespon ancaman masalah ekonomi justru dapat melahirkan masalah baru yang mengarah pada permanent emergency karena Perppu yang dibentuk setingkat undang-undang memiliki jangkauan yang luas dan dapat mengubah secara permanen tatanan yang sudah dibangun sejak awal, seperti pemberian kekebalan hukum pada pejabat pelaksana untuk tidak dapat dituntut secara perdata, pidana maupun administrasi sebagaimana diatur dalam Pasal 29 Perppu

\footnotetext{
${ }^{5} \mathrm{Hal}$ Hill, The Indonesian Economy in Crisis, Causes, Consequences, and Lessons, Singapura: Institute of Southeast Asian Studies, 1999, hlm. 71-73.
} 
4/2008. Akibatnya, Perppu tersebut ditolak pengesahannya oleh DPR. Namun, kendati Perppu 4/2008 ditolak DPR, pada praktiknya justru diabaikan oleh pelaksana kekuasaan. Hendrawan Supratikno mencatat, sejak Perppu 4/2008 ditolak DPR, aktifitas yang diatur dalam Perppu tersebut justru masih dilakukan oleh LPS seperti dalam pemberian dana talangan pada Bank yang terdampak sistemik mencapai Rp2.8 Triliun. ${ }^{6}$

Praktik yang sama kemudian juga dilakukan melalui Perppu 1/2020 yang juga memberikan imunitas pada organ pelaksana perppu. Jika dilihat, konsep imunitas dalam Perppu 1/2020 masih mengadopsi konsep yang sama dengan yang diatur dalam Perppu 4/2008. Anehnya, Perppu 1/2020 justru disetujui oleh DPR menjadi UU 2/2020 di mana sebelumnya konsep imunitas tersebut ditolak oleh DPR Tahun 2008.

Penulis berpendapat penggunaan Perppu sebagai instrumen merespon ancaman ekonomi sebagaimana dipraktikkan di atas tidak tepat karena beberapa hal: Pertama, penggunaan perppu justru akan mengubah seluruh tatanan pemulihan ekonomi menjadi permanen terlebih jika perppu tersebut menjadi undang-undang. Padahal, tujuan awal lahirnya perppu adalah untuk merespon ancaman ekonomi secara temporer agar dapat kembali seperti semula, dengan tidak adanya batasan waktu dalam perppu, maka upaya pemulihan ekonomi akan otomatis terus berlaku. ${ }^{7}$ Praktik ini menjadikan suatu ancaman ekonomi akan terus menjadi ancaman (pemanent threats) kendati sudah berhasil dipulihkan dan imunitas hukum pelaksana perppu akan terus berlaku sepanjang aktifitasnya mengatasnamakan perppu tersebut.

Kedua, secara hukum, perppu bukan merupakan produk hukum yang didesain untuk merespon ancaman keadaan bahaya, melainkan untuk mempermudah pemerintah menjalankan kebijakan jika terkendala proses pembentukan undang-undang yang panjang. Hal ini sebagaimana dipertegas dalam Putusan MK No. 138/PUU-VII/2009 yang menafsirkan prasa "kegentingan yang memaksa" harus memenuhi unsur adanya kebutuhan mendesak untuk menyelesaikan masalah hukum secara cepat berdasarkan undang-undang. Kemudian, belum terdapat undang-undang yang mengatur masalah hukum tersebut, sehingga terjadi kekosongan hukum, atau sudah ada undang-undang yang mengatur namun tidak memadai. Selanjutnya, kekosongan hukum tersebut tidak

\footnotetext{
${ }^{6}$ Hendrawan Supratikno, Ekonomi Nurani VS Ekonomi Naluri, Jakarta: Yayasan Pustaka Obor Indonesia, 2011, hlm. 278.

${ }^{7}$ Meskipun Pasal 22 ayat 2 UUDNRI 1945 dan Pasal 52 UU 12/2011 mengatur bahwa perppu harus mendapatkan persetujuan pada masa sidang berikutnya, namun persetujuan atau penolakan oleh DPR bersifat politis, terbukti sampai hari ini nomenklatur Perppu 23/1959 dan Perppu 22/1960 masih digunakan kendati UU 1/1961 telah menyatakan semua perppu dan UU Drt yang dibentuk sebelum tahun 1961 disahkan menjadi undang-undang. Namun, Perppu 23/1959 masih terus digunakan sebagai dasar hukum keadaan bahaya, seperti penerapan darurat sipil dan militer pada Tahun 2003 di Aceh. Terlebih, secara hukum tidak ada ketentuan baik secara eksplisit maupun implisit yang mengatur mengenai status perppu jika tidak direspon oleh DPR pada masa sidang berikutnya, apakah otomatis tidak berlaku atau tetap berlaku, karena UUDNRI 1945 dan UU 12/2011 hanya mengatur bahwa perppu harus mendapatkan persetujuan pada masa sidang berikutnya, dan tidak ada aturan mengenai konsekuensi jika perppu yang diajukan tidak mendapatkan respon dari DPR.
} 
dapat diatasi dengan cara membuat undang-undang melalui prosedur biasa, sedangkan keadaan yang mendesak tersebut memerlukan kepastian untuk diselesaikan. ${ }^{8}$

Berdasarkan dua alasan tersebut, penulis berpendapat bahwa ancaman ekonomi justru dapat dikategorikan sebagai ancaman keadaan bahaya karena dampaknya bersifat mengancam keamanan negara. Pendapat ini juga sesuai dengan pandangan Carl Schmitt yang berpendapat bahwa ancaman masalah ekonomi memiliki karakter yang sama dengan ancaman perang dan pemberontakan di mana stabilitas ekonomi sangat berkaitan dengan stabilitas politik, dan dengan stabilitas politik, negara lebih mampu merespon dan mengatasi ancaman perang dan pemberontakan. ${ }^{9}$

Saat ini, ancaman ekonomi belum diatur sebagai bagian dari keadaan bahaya, sehingga penting untuk memiliki format pengaturan ancaman ekonomi dalam keadaan bahaya. Oleh sebab itu, tulisan ini akan mengkaji bagaimana praktik pemerintah dalam merespon ancaman ekonomi berdasarkan konsep keadaan bahaya. Pembahasan dalam tulisan ini akan mengulas mengenai konsep keadaan bahaya dan format penataan keadaan bahaya dalam merespon ancaman ekonomi.

\section{PEMBAHASAN}

\section{Konseptual Keadaan Bahaya dalam Peraturan di Indonesia}

Keadaan bahaya merupakan terminologi yang sulit dijelaskan karena jika mengacu pada keadaan bahaya sebagai ancaman (threats), maka terdapat benyak keadaan yang sifatnya mengancam atau menjadi faktor lahirnya keadaan yang mangancam. Terkait hal tersebut, Scott M. Matheson menyebutnya sebagai "emergency continuum" di mana ancaman tidak diketahui kapan terjadinya dan kapan berakhirnya karena terdapat banyak jenis ancaman yang dapat terjadi kapanpun sebagaimana dijelaskan lebih lanjut oleh Scott M. Matheson "Threats to the nation come in many forms-natural disaster, economic crisis, food contamination, disease epidemics, and wars" ${ }^{10}$ Sedangkan secara teori, keadaan bahaya dipahami secara berbeda antara penganut teori state of exeption dan teori state of emergency. Penganut teori state of exeption berpendapat bahwa praktik keadaan bahaya berada di luar ranah hukum dan dapat menyimpang dari peraturan apapun. ${ }^{11}$ Sedangkan, penganut teori state of emergency berpendapat keadaan bahaya menjadi bagian dari ranah hukum yang memberikan Presiden kekuasaan khusus sebagaimana pendapat Oren Gross "Emergency powers operate in a legal sphere different and distinct from that occupied by the ordinary legal system". ${ }^{12}$ Terkait kedua teori tersebut, Penulis berpandangan

\footnotetext{
${ }^{8}$ Lihat, Putusan Mahkamah Konstitusi Nomor 138/PUU-VII/2009 poin 3.10, hlm. 19.

9 William E. Scheuerman, "The Economic State of Emergency" makalah dipresentasikan pada International Conference on Carl Schmitt, diselenggarakan oleh Columbia University, Cardozo Law School, New School, New York, pada 23-25 April 1999, hlm. 1-6.

${ }^{10}$ Scott M. Matheson, Presidential Constitutionalism in Perilous Times, Cambridge: Harvard University Press, 2009, hlm. 9.

${ }^{11}$ Andrew Norris, "Sovereignty, Exception, and Norm", Journal of Law and Society, Volume 34, No. 1, 2007, hlm. 31-45.

${ }^{12}$ Oren Gross, Fionnuala Ni Aolain, Law in Times of Crisis: Emergency Powers in Theory and Practice, Cambridge: Cambridge University Press, 2006, hlm. 35.
} 
bahwa konsep keadaan bahaya yang dianut oleh Indonesia cenderung mengadopsi teori state of emergency, karena perihal keadaan bahaya diatur melalui konstitusi dan undangundang.

Konseptual keadaan bahaya di Indonesia merujuk pada pengaturan keadaan bahaya dalam Pasal 12 UUD NRI 1945. Merujuk pada original intent, konsep Pasal 12 UUD NRI 1945 merujuk pada konsep keadaan bahaya yang diatur dalam Indische Staatsregeling (I.S; Stbld 1925 No. 415 jo 577) dan Regeling Op Den Staat van Oorlog en van Beleg (S.O.B; Stbld. 1939 No. 582) yang mengatur dua tingkatan keadaan bahaya yaitu staat van oorlog $(\mathrm{SvO})$ dan staat van beleg $(\mathrm{SvB})$. Kedua peraturan tersebut menjelaskan $\mathrm{SvO}$ sebagai keadaan perang yang digunakan untuk mengatasi ancaman militer dari pihak asing, sedangkan SvB diartikan sebagai keadaan darurat perang yang digunakan untuk mengatasi ancaman dari internal negera. Kabul Arifin menjelaskan perbedaan SvO dan SvB sebagai berikut:

"Di dalam pasal tersebut diadakan perbedaan jang tegas antara tingkatan itu, di mana dapat ditarik kesimpulan bahwa ada suatu differensiasi antara kedua pengertian itu. Adapun perbedaan itu bukanlah merupakan suatu perbedaan jang mutlak, akan tetapi hanja suatu perbedaan jang bersifat gradueel, oleh karena baik dalam tingkatan keadaan perang, maupun di dalam tingkatan keadaan darurat perang, mala kekuasaan militer adalah jang tertinggi, adalah terdapat suatu supremasi dari militair gezag". ${ }^{13}$

Konsep SvB kemudian diadopsi dalam Pasal 12 UUDNRI 1945, sebagaimana tercatat dalam risalah sidang pembentukan UUD 1945 yang menggunakan istilah SvB untuk menyebut "keadaan bahaya". Istilah SvB kemudian disempurnakan oleh panitia bahasa menjadi "keadaan bahaya". ${ }^{14}$ Selain dalam UUD 1945, konsep S.O.B juga diadopsi dalam dua konstitusi yang pernah berlaku seperti Konstitusi RIS dan UUDS 1950. Konstitusi RIS mengatur keadaan bahaya melalui Pasal 184 ayat 1 KRIS sebagai berikut:

"Dengan cara dan dalam hal-hal yang akan ditentukan dengan undang-undang federal, Pemerintah dapat menyatakan daerah Republik Indonesia Serikat atau bagian-bagian dari padanya dalam keadaan perang atau dalam keadaan darurat perang, sekadar dan selama ia menganggap hal itu perlu untuk kepentingan keamanan dalam negeri dan keamanan luar negeri."

Kemudian, Pasal 129 ayat 1 UUDS 1950 mengatur keadaan bahaya sebagai berikut: "Dengan tjara dan dalam hal-hal jang akan ditentukan dengan undang-undang, Presiden dapat menjatakan daerah Republik Indonesia atau bagian-bagian dari

13 Kabul Arifin, et.al, Pokok-Pokok Pengertian dan Beberapa Persoalan Tentang S.O.B. Jakarta: Penerangan Angkatan Darat, 1957, hlm. 15.

14 Saafroedin Bahar et. al, Risalah Sidang Badan Penyelidik Usaha-usaha Persiapan Kemerdekaan Indonesia (BPUPKI) Panitia Persiapan Kemerdekaan Indonesia (PPKI), Jakarta: Sekretariat Negara Republik Indonesia, 1993, hlm. 199. 
padanja dalam keadaan bahaja, bilamana ia menganggap hal itu perlu untuk kepentingan keamanan dalam negeri dan keamanan terhadap luar negeri."

Selain diadopsi dalam konstitusi, konsep S.O.B kemudian juga diadopsi melalui beberapa undang-undang seperti dalam UU 6/1946 dan UU 74/1957. Modifikasi konsep S.O.B kemudian dilakukan melalui Perppu 23/1959 dengan menambahkan satu tingkatan yaitu darurat sipil, sedangkan dua tingkatan lainnya $(\mathrm{SvB}$; darurat militer dan $\mathrm{SvO}$; keadaan perang) masih mengadopsi konsep S.O.B.

Pasal 12 UUDNRI 1945 mengatur mengenai kekuasaan dalam keadaan bahaya hanya dimiliki oleh Presiden karena jabatannya sebagai kepala negara. Konsep kekuasaan ini juga merujuk pada ketentuan S.O.B yang mengatur kekuasaan dalam keadaan bahaya dipegang oleh Gubernur Jenderal sebagaimana diatur dalam Pasal 1 S.O.B "Elk gedeelte van Indonesie kan, bij besluit van den Gouv.-Gen, in staat van oorlog of in staat van beleg worden verklaard, wanneer naar zijn oordeel" (Setiap bagian dari Indonesia, yang diputuskan oleh Gubernur Jenderal, dapat dinyatakan dalam keadaan perang atau dalam keadaan darurat perang, ketika menurut pendapatnya).

Presiden dalam menjalankan kekuasaan keadaan bahaya tidak dapat diintervensi oleh siapapun termasuk oleh DPR. Ketentuan tersebut dapat dilihat dalam penjelasan umum angka 2 Perppu 23/1959 yang berbunyi “...juga tidak diadakan pengawasan oleh Dewan Perwakilan Rakyat terhadap sesuatu pernyataan keadaan bahaya oleh Presiden, karena tidak sesuai dengan kedudukan Presiden menurut Undang-undang Dasar yang hanya bertanggung jawab terhadap Majelis Permusyawaratan Rakyat”. Konsep tersebut juga merujuk pada konseideran S.O.B yang berbunyi “Overwegende, voorts, dat zich hier een geval vootdoet van spoedeischenden aard, als voorzien in den aanhef van art.70 der Ind. Staatsreg., waarin de Volksraad niet kan worden gehoord" (menimbang, selanjutnya, bahwa karena keadaan bahaya yang bersifat mendesak, sebagaimana diatur dalam Pembukaan Pasal 70 Ind. State Reg., Volksraad tidak dapat didengar pendapatnya).

Pasal 12 UUDNRI 1945 tidak mengatur secara jelas mengenai jenis-jenis ancaman yang dapat dikategorikan sebagai bagian keadaan bahaya. Namun, sejak dibentuknya UU 6/1946, Indonesia mulai mengenal jenis ancaman yang dapat dikategorikan sebagai bagian keadaan bahaya. UU 6/1946 mengatur empat jenis ancaman keadaan bahaya meliputi: serangan, bahaya serangan, pemberontakan atau perusuhan, dan bencana alam. Jenis ancaman tersebut juga masih mengadopsi jenis ancaman yang diatur dalam S.O.B sebagaimana diatur dalam Pasal 1 ayat 1 angka 2 e S.O.B sebagai berikut: "de inwendige veiligheid in gevaar verkeert, hetzij door binnenlandsche onlusten, waarbij te vreezen valt, dat niet met de gewone machtsmiddelen zal kunnen worden volstaan, hetzij door ontwrichting van het burgerlijk gezag tengevolge van rampen" (dalam hal ketika keamanan negara dalam keadaan bahaya, baik disebabkan masalah internal yang menyebabkan ketakutan di mana alat kekuasaan negara tidak cukup untuk mengatasinya serta terjadi gangguan yang disebabkan masalah sipil dan bencana alam). Jenis ancaman 
yang diatur dalam S.O.B kemudian selanjutnya diadopsi dalam setiap undang-undang yang mengatur muatan keadaan bahaya seperti dalam UU 74/1957 dan Perppu 23/1959.

Berdasarkan kajian konseptual di atas, dapat disimpulkan, bahwa keadaan bahaya yang diatur dalam Pasal 12 UUDNRI 1945 mengadopsi konsep S.O.B di mana Presiden memiliki kewenangan menyatakan keadaan bahaya yang jenis-jenis ancamannya sebagaimana diatur dalam undang-undang keadaan bahaya. Saat ini, undang-undang yang mengatur muatan keadaan bahaya terdiri dari empat undang-undang yaitu: Perppu 23/1959, UU 24/2007, UU 7/2012 dan UU 6/2018. Menariknya, ancaman ekonomi tidak termasuk sebagai ancaman keadaan bahaya. Padahal, Tahun 1952, Soekarno pernah menyatakan keadaan perang untuk menghadapi ancaman ekonomi melalui Keppres Keppres 176/1952. Keppres tersebut dibentuk saat terjadinya banyak penyelundupan barang dan orang ke dalam wilayah Indonesia melalui wilayah perairan yang dikhawatirkan mengancam stabilitas ekonomi negara. Oleh sebab itu, Soekarno memberlakukan keadaan perang di seluruh wilayah perairan Indonesia (territoriale wateren). Dari praktik tersebut, dapat dipahami, bahwa jangkauan ancaman keadaan bahaya tidak terbatas pada jenis ancaman yang telah diatur dalam undang-undang saja, melainkan juga pada ancaman yang belum diatur seperti ancaman ekonomi.

\section{Masalah Ekonomi sebagai Ancaman Keadaan Bahaya}

Perkembangan ancaman keadaan bahaya di era modern saat ini menjadi tantangan khusus bagi negara-negara demokrasi di mana ancaman keadaan bahaya yang terjadi bersifat multikarakter baik ancaman yang bersifat militer maupun nonmiliter dan seringkali keduanya terjadi bersamaan. Anna Khakee berpendapat bahwa perkembangan keadaan bahaya yang beragam harus direspon secara berbeda sesuai dengan sifatnya "Emergency situations differ greatly: pandemics and natural catastrophes tend to have different effects and require different responses than insurgencies or attempted coups d'état. Terrorist attacks, again, will be different from severe economic crises or an armed aggression of a foreign state". ${ }^{15}$ Oleh sebab itu, banyak negara membentuk peraturan untuk merespon ancaman keadaan bahaya yang memiliki karakter beragam, salah satunya ancaman masalah ekonomi.

Salah satu negara yang mengatur ancaman ekonomi sebagai bagian keadaan bahaya adalah Amerika Serikat melalui International Emergency Economic Powers Act (IEEPA) Tahun 1977. Undang-undang tersebut mengatur kekuasaan presiden terhadap masalah ekonomi setelah pemberlakukan keadaan bahaya. IEEPA sendiri merupakan aturan lanjutan dari National Emergency Act 1976. Perkembangan IEEPA di era modern digunakan oleh Amerika Serikat sebagai instrumen untuk menerapkan kebijakan internasional di bidang ekonomi. ${ }^{16}$ Pasal 203 IEEPA memberikan kewenangan pada

\footnotetext{
${ }^{15}$ Anna Khakee, Securing Democracy? A Comparative Analysis of Emergency Powersin Europe, Policy Paper No. 30, Jenewa: Geneva Centre for the Democratic Control of Armed Forces (DCAF), 2009, hlm. 10.

${ }^{16}$ Christopher A. Casey, et al, The International Emergency Economic Powers Act: Origins, Evolution, and Use, Washington: Congressional Research Service, 2020, hlm. 25.
} 
Presiden Amerika setelah menyatakan keadaan bahaya untuk melakukan beberapa hal meliputi:

"to investigate, regulate, or prohibit foreign exchange transactions, transfers of credit, transfers of securities, payments, and may take specified actions relating to property in which a foreign country or person has interest-freezing assets, blocking property and interests in property, prohibiting U.S. persons from entering into transactions related to frozen assets and blocked property, and in some instances denying entry into the United States."

Kewenangan yang diberikan IEEPA tersebut dipraktikkan apabila ancaman ekonomi mulai berdampak pada keamanan negara dengan ditandai adanya pernyataan keadaan bahaya. Setelah pernyataan keadaan bahaya ditetapkan, selanjutnya Presiden Amerika dapat menggunakan Pasal 203 IEEPA untuk membentuk kebijakan-kebijakan dalam upaya penyelamatan ekonomi. ${ }^{17}$

Praktik Amerika Serikat dalam merespon ancaman keadaan ekonomi juga dilakukan saat terjadi krisis global 2008 akibat gagalnya sub-prime mortgage. Amerika Serikat kemudian merespon masalah sub-prime mortgage dengan membentuk Emergency Economic Stabilization Act (EESA) 2008 yang memberikan kewenangan pada menteri keuangan untuk membeli aset bermasalah yang disebabkan masalah subprime mortgage. EESA mengatur ancaman krisis finansial tersebut sebagai sebuah ancaman terhadap stabilitas ekonomi, sehingga melalui EESA pemerintah dapat membentuk kebijakan darurat untuk menyelamatkan ekonomi. ${ }^{18}$

Di era modern, ancaman ekonomi dapat disebut sebagai bentuk ancaman yang paling berpotensi melemahkan suatu negara karena perang ekonomi lebih memiliki dampak daripada perang militer, karena tanpa kekuatan ekonomi, negara tidak akan mampu memiliki pertahanan yang kuat. Praktik ini juga telah dilakukan pada perang dunia kedua di mana target perang selalu dilakukan pada objek ekonomi suatu negara. ${ }^{19}$

Dilihat dari potensinya, ancaman ekonomi dapat lahir dari dua faktor eksternal maupun internal. Faktor eksternal memberikan peluang terhadap ancaman ekonomi seperti dampak perang dagang maupun sanksi ekonomi yang dilakukan oleh suatu negara terhadap negara atau korporasi melalui pembatasan perdagangan, tariff atau embargo ekonomi. Terkait sanksi ekonomi, William H. Kaempfer dan Anton D. Lowenberg berpendapat sebagai berikut:

"International economic sanctions are often favored by nation states or by international organizations as a means of projecting power or influencing another

\footnotetext{
${ }^{17}$ Patrick Thronson, "Toward Comprehensive Reform of America's Emergency Law Regime," Michigan Journal of Law Reform, Volume 46, No. 2, 2013, hlm. 757-759.

${ }_{18}$ Joshua S. Hanan dan Catherine Chaput, "Stating the Exception: Rhetoric and Neoliberal Governance During the Creation and Passage of the Emergency Economic Stabilization Act of 2008", Journal of Argumentation and Advocacy, Volume 50, No. 1, 2013, hlm. 18-33.

19 Alan S Milward, War, Economy and Society, 1939-1945, Los Angeles: University of California Press, 1979, hlm. 4.
} 
government's behavior without resorting to military conflict. The utility of sanctions as an instrument of foreign policy is attested to both by their longevity as a staple of international diplomacy and by their growing popularity since the end of the Cold War". ${ }^{20}$

Ancaman ekonomi dari faktor eksternal tersebut dapat memberikan dampak ekonomi seperti krisis maupun resesi ekonomi pada negara terdampak. Terkait sanksi ekonomi, General Agreement on Tariffs and Trade (GATT) mengatur bahwa perjanjian perdagangan yang dilakukan oleh negara-negara melarang adanya pemberian sanksi ekonomi pada negara lain, namun terdapat pengecualian jika hal tersebut dilakukan atas nama keadaan bahaya sebagaimana diatur dalam Pasal XXI GATT. ${ }^{21}$ Oleh sebab itu, meskipun beberapa perjanjian internasional memperketat pemberian sanksi ekonomi, namun atas dasar keadaan bahaya semua dapat dibenarkan, dengan demikian tidak ada negara yang terbebas dari potensi ancaman ekonomi.

Selain faktor eksternal, faktor internal juga menjadi potensi lahirnya ancaman ekonomi yang disebabkan kebijakan yang salah, korupsi hingga bencana. Ancaman ekonomi yang dirasakan oleh semua negara saat ini adalah ancaman resesi ekonomi akibat dampak bencana yang disebabkan penyebaran Covid-19. Terkait resesi, National Bureau Economic Reasearch (NBER) menjelaskannya sebagai berikut:

"a recession as two or more consecutive quarters of negative GDP growth. This implies that expansion is two or more consecutive quarters of positive GDP growth. The peak of an expansion is the point in time at which the level of GDP reaches its maximum before it starts to decline. Thus, the peak of an expansion dates the beginning of recession". ${ }^{22}$

Jika melihat dari penjelasan di atas, maka Indonesia merupakan salah satu negara yang telah masuk dalam resesi ekonomi karena syarat terjadinya resesi telah terpenuhi di mana pertumbuhan ekonomi Indonesia pada kuartal pertama menurun ke angka 2,97\% dari sebelumnya 5,2\%, kemudian semakin menurun pada kuartal kedua dan ketiga menjadi minus. ${ }^{23}$ Resesi ekonomi yang terjadi menyebabkan ancaman yang lebih besar terhadap keamanan negara. Muhumed Mohamed Muhumed sebagaimana mengutip

\footnotetext{
${ }^{20}$ William H. Kaempfer dan Anton D. Lowenberg, "Chapter 27: The Political Economy of Economic Sanctions" dalam Todd Sandler dan Keith Hartley, Handbook of Defense Economics, Volume 2, Amsterdam: North-Holland Publishing, 2007, hlm. 869.

${ }^{21}$ Siamack Shojai dan Patricia S. Root, "Effectiveness Of Economic Sanctions: Empirical Research Revisited”, International Business \& Economics Research Journal, Volume 12, No. 11, 2013, hlm. 14791490.

22 Todd A. Knoop, Recessions and Depressions: Understanding Business Cycles, Westport: Praeger Publisher, 2004, hlm. 11-12. Lihat juga, Saul Eslake, "The Difference between a Recession and a Depression", Economic Papers A Journal of Applied Economics and Policy, Volume 28, No. 2, 2009, hlm. 75-81.

${ }^{23}$ Badan Pusat Statistik, Laporan Perekonomian Indonesia 2020, Jakarta: BPS RI, 2020, hlm. 41
} 
Crumley dan Karon berpendapat bahwa krisis finansial dan resesi ekonomi dapat menyebabkan tiga jenis ancaman terhadap keamanan negara sebagaimana berikut:

"Firstly, long-lasting economic recession accompanied with lower levels of production, investment, consumption, government spending as well as higher levels of unemployment and possibly inflation will lead to regime collapse. That vacuum and state failure will therefore give chance to terrorists, pirates and other violent groups. Secondly, crisis is associated with rising nationalism. This can be either rising anti-immigrant movements in developed countries, or promoting protectionism policies in developing countries. This disintegration between economies undermines the possibility of collaboration and economic recovery. Thirdly, due to increasing unemployment, both activities and power of organized criminal groups rises that deteriorates the security in national and international levels". ${ }^{24}$

Pendapat di atas menunjukkan bahwa ancaman resesi ekonomi akan menyebabkan suatu negara mengalami masalah yang lebih besar seperti masalah sosial, hukum, ekonomi dan politik. Kondisi tersebut juga pernah dialami Indonesia Tahun 1998 di mana krisis ekonomi yang terjadi sudah dikategrorikan sebagai depresi ekonomi sebagaimana pendapat Saul Eslake "The 18 per cent contraction in Indonesia's GDP during 1998 would also qualify as a "depression" under the first of the aforementioned definitions". Krisis ekonomi tersebut menjadi salah satu penyebab runtuhnya pemerintahan orde baru pada Tahun $1998 .^{25}$

Berdasarkan penjelasan di atas, dapat disimpulkan jika ancaman ekonomi merupakan ancaman nonmiliter yang memiliki dampak besar terhadap keamanan nasional jika tidak diantisipasi dan ditanggulangi dengan mekanisme yang baik. Sejarah mencatat, bahwa ancaman krisis ekonomi Tahun 1998 merupakan ancaman yang besar dan menimbulkan masalah di berbagai sektor sosial, hukum, ekonomi dan politik. Bentuk respon terhadap ancaman ekonomi juga tidak dapat dilakukan dengan cara biasa lazimnya praktik penanggulangan ancaman dalam keadaan normal, karena dampaknya yang mengancam keamanan negara, maka harusnya ancaman ekonomi dikategorikan sebagai bagian keadaan bahaya, sehingga dengan mekanisme keadaan bahaya pemerintah memiliki kendali penuh atas kebijakan untuk memulihkan kondisi ekonomi.

\section{Penataan Ancaman Ekonomi dalam Keadaan Bahaya di Indonesia}

Konsep keadaan bahaya Indonesia memiliki karakteristik yang berbeda dari konsep keadaan bahaya yang umum dipraktikkan pada negara dengan sistem presidensil seperti

\footnotetext{
${ }^{24}$ Muhumed Mohamed Muhumed, "The Effect of Financial Crisis on International Security", diakses pada https://www.researchgate.net/publication/311867747 pada tanggal 6 Oktober 2020 pukul 21.05.

${ }^{25}$ Vedi R. Hadiz, "Retrieving the Past for the Future? Indonesia and the New Order Legacy", Southeast Asian Journal of Social Science, Volume 28, No. 2, 2000, hlm. 11-33.
} 
Amerika Serikat, Prancis dan Filipina. ${ }^{26}$ Ketiga negara tersebut mengatur keadaan bahaya secara terukur dan jelas tanpa adanya tumpang tindih pengaturan, sedangkan Indonesia mengatur keadaan bahaya secara berlapis dan tumpang tindih antar undang-undang. Dalam artikel sebelumnya yang berjudul "Ambiguitas Pengaturan Keadaan Bahaya dalam Sistem Ketatanegaraan Indonesia", Penulis menjelaskan mengenai pengaturan jenis ancaman keadaan bahaya secara tumpang tindih dalam beberapa undang-undang yang menyebabkan ambiguitas konsep keadaan bahaya baik mengenai kekuasaan, batas waktu dan format pertanggungjawaban. ${ }^{27}$ Oleh sebab itu, sebelum menata ancaman ekonomi dalam keadaan bahaya terlebih dahulu harus diluruskan mengenai pengaturan ideal keadaan bahaya agar proses penataan ancaman ekonomi dalam keadaan bahaya dapat dilakukan secara tepat.

Merujuk pada konsep keadaan bahaya sebagaimana diatur dalam Pasal 12 UUDNRI 1945, keadaan bahaya harusnya diatur dalam satu undang-undang khusus yang di dalamnya mengatur mengenai praktik hukum tata negara darurat. Sebelumnya, Perppu 23/1959 merupakan satu-satunya yang mengatur muatan keadaan bahaya namun karena perkembangan jenis ancaman yang lebih beragam dan perubahan paradigma keadaan bahaya yang lebih demokratis, Perppu 23/1959 dianggap tidak lagi sesuai dengan perkembangan. Namun, beberapa rancangan undang-undang yang dibentuk untuk menggantikan Perppu 23/1959 belum juga disetujui oleh Presiden dan DPR seperti RUU Penanggulangan Keadaan Bahaya (RUU PKB) dan RUU Keamanan Nasional. Oleh sebab itu, lahir tiga undang-undang (UU 24/2007, UU 7/2012 dan UU 6/2018) yang mengatur ancaman nonmiliter seperti bencana, konflik hingga penyakit justru menimbulkan pengaturan berlapis karena jenis ancaman yang diatur juga terdapat dalam Perppu 23/1959, sehingga terdapat dua puluh enam jenis ancaman yang dikategorikan sebagai ancaman keadaan bahaya. ${ }^{28}$ Selain jenis ancaman yang diatur berlapis, kekuasaan juga diatur secara kontradiktif antara Presiden dan kepala daerah, hal tersebut belum termasuk organ pelaksana dan batasan waktu serta format pertanggungjawaban yang seluruhnya juga diatur secara berlapis.

Sebagaimana telah dijelaskan sebelumnya, bahwa kewenangan dalam keadaan bahaya harus sepenuhnya dipegang oleh Presiden selain karena kedudukannya sebagai

\footnotetext{
${ }^{26}$ Konsep keadaan bahaya pada ketiga negara tidak dipegang secara absolut oleh presiden melainkan harus mendapat persetujuan dari kongres, di mana Kongres memiliki peran dominan dalam mengawasi praktik kekuasaan presiden. Lihat, National Emergency Act 1976. Lihat, Pasal 16 dan 36 Konstitusi Prancis. Lihat pula Pasal BAB VI Pasal 23 Ayat 1 dan 2 Konstitusi Filipina

27 Agus Adhari, "Ambiguitas Pengaturan Keadaan Bahaya dalam Sistem Ketatanegaraan Indonesia", Dialogia Iuridica: Jurnal Hukum Bisnis dan Investasi, Volume 11, No. 1, 2019, hlm. 43-61.

${ }^{28}$ Dua puluh enam jenis ancaman tersebut adalah: 1. Pemberontakan (kerusuhan bersenjata), 2. Kerusuhan, 3. Perang Saudara, 4. Bencana Alam, 5. Perang yang diatur dalam Perppu 23/1959. UU 24/2007 mengatur empat belas jenis keadaan bahaya sebagai berikut: 1. Gempa Bumi, 2. Tsunami, 3. Gunung Meletus, 4. Banjir, 6. Kekeringan, 7. Angin Topan, 8. Tanah Longsor, 9. Gagal Teknologi, 10. Gagal Modernisasi, 11. Epidemi, 12. wabah penyakit, 13. Konflik sosial, 14. Teror. UU 7/2012 mengatur satu jenis keadaan bahaya yaitu konflik sosial. UU 6/2018 mengatur enam jenis keadaan bahaya sebanyak enam jenis sebagai berikut: 1. Penyakit Menular, 2. Radiasi Nuklir, 3. Pencemaran Biologi, 4. Kontaminasi Kimia, 5. Bioterorisme, 6. Pangan.
} 
kepala negara dan kepala pemerintahan, juga untuk mempermudah perintah terhadap organ pelaksana. Kemudian selama keadaan bahaya ditetapkan, Presiden diberikan kewenangan khusus untuk membentuk kebijakan yang luas namun dalam waktu terbatas untuk mengatasi ancaman. Pembatasan waktu diberikan agar penetapan keadaan bahaya dalam praktik kekuasaan tidak mengarah pada penyalahgunaan kekuasaan serta untuk menghindari permanent emergency yang justru bertentangan dengan konsep keadaan bahaya. ${ }^{29}$ Dengan demikian, keadaan bahaya dapat dipahami sebagai peralihan format kekuasaan dalam bidang tertentu dari praktik hukum tata negara normal yang terikat prinsip checks and balances menjadi hukum tata negara darurat yang memberikan kekuasaan khusus pada Presiden selama waktu terbatas di mana praktik checks and balances ditangguhkan sampai dengan akhir batas waktu kekuasaan khusus diberikan.

Setelah konsep keadaan bahaya dapat dipahami, maka mengenai penataan ancaman ekonomi dalam keadaan bahaya dilakukan dalam beberapa tahapan. Pertama, penentuan jenis ancaman ekonomi. Terkait jenis ancaman, Penulis telah menjelaskan mengenai faktor lahirnya ancaman ekonomi baik eksternal maupun internal yang dapat melahirkan beberapa jenis ancaman seperti pembatasan perdagangan (trade barrier), tariff, pembatasan transaksi keuangan (restrictions on financial transactions), embargo dan sanksi ekspor. ${ }^{30}$ Selain jenis tersebut, ancaman ekonomi lain seperti krisis ekonomi, resesi dan depresi ekonomi juga termasuk jenis ancaman ekonomi. Jenis ancaman tersebut diatas kemudian harus diatur sebagai bagian dari ancaman ekonomi dalam keadaan bahaya. Untuk memberikan kepastian, pengaturan jenis ancaman ekonomi tersebut harus terlebih dahulu ditentukan mengenai batas minimum suatu ancaman ekonomi dapat dikategorikan mengancam keamanan negara. Terkait hal ini, Penulis mengusulkan dua format untuk menentukan apakah ancaman ekonomi dapat dikategorikan mengancam keamanan negara. Format pertama, terhadap ancaman yang berasal dari faktor eksternal, batas minimum adalah dampak terhadap perekonomian nasional, semakin besar dampak sanksi ekonomi terhadap perekonomian nasional, maka Presiden dapat menetapkan keadaan bahaya untuk merespon ancaman tersebut. Format kedua, terhadap ancaman dari internal, batas minimum adalah tingkat pertumbuhan ekonomi. Jika pertumbuhan ekonomi nasional terkontraksi pada angka minus, maka Presiden dapat menetapkan keadaan bahaya untuk merespon ancaman ekonomi tersebut. ${ }^{31}$

\footnotetext{
${ }^{29}$ Mark Neocleous, “The Problem with Normality: Taking Exception to "Permanent Emergency", Journal of Alternatives Global, Local, Political, Volume 31, No. 2, 2006, hlm. 191-213.

${ }^{30}$ Jamal Ibrahim Haidar berpendapat bahwa embargo dan sanksi ekspor berbeda "Export sanctions are different from embargoes: while export sanctions represent higher export costs (they raise cost of exporting at the exporter-destination level), embargoes represent a shift to autarky via a trade blockade". Lihat, Jamal Ibrahim Haidar, "Sanctions and export deflection: Evidence from Iran", Journal Economic Policy, Volume 32, No. 90, 2017, hlm. 319-355.

${ }^{31}$ Terkait usulan mengenai batas minimum ancaman di atas, Penulis hanya sebatas memberikan gambaran, tentu jika terdapat unsur yang lebih tepat digunakan sebagai batas minimum ancaman, maka akan lebih baik. Namun, usulan yang terpenting adalah mengatur mengenai batasan minimum suatu jenis ancaman dapat dikategorikan mengancam keamanan negara, karena konsep keadaan bahaya memiliki syarat adanya ancaman terhadap keamanan negara.
} 
Kedua, ruang lingkup kekuasaan Presiden dalam merespon ancaman ekonomi. Meskipun dalam keadaan bahaya Presiden diberikan kekuasaan khusus, namun kekuasaan khusus tersebut harus dibatasi hanya terkait masalah ekonomi. Seperti membentuk kebijakan temporer terkait ancaman ekonomi. Merujuk pada beberapa praktik yang pernah dilakukan saat merespon krisis global 2008 dan resesi ekonomi 2020, Presiden membentuk kebijakan keuangan negara dan kebijakan stabilitas sistem keuangan sebagaimana diatur dalam Perppu 1/2020 (UU 2/2020), kebijakan yang sama juga pernah diatur dalam Perppu 4/2008 yang mengatur mengenai JPSK. Adapun kebijakan yang dilakukan terpusat pada pengalihan APBN pada bentuk bantuan keuangan seperti stimulus, bailout dan bantuan keuangan terhadap sektor terdampak. Kebijakan tersebut juga dilakukan sebagian besar negara seperti Amerika Serikat melalui EESA dan Malaysia. ${ }^{32}$ Untuk mengatur ruang lingkup kekuasaan Presiden dalam merespon ancaman ekonomi, maka beberapa ruang lingkup kebijakan yang dapat dilakukan seperti kebijakan penggunaan APBN, kebijakan fiskal, kebijakan terkait harga, investasi, perdagangan, pajak dan lain-lain. Jikapun harus menggunakan perppu sebagai instrumen, maka dalam perppu juga harus diatur bahwa kebijakan tersebut hanya berlaku sepanjang pernyataan keadaan bahaya diberlakukan.

Ketiga, penataan terhadap batasan waktu penerapan keadaan bahaya dalam merespon ancaman ekonomi. Empat undang-undang yang mengatur muatan keadaan bahaya mengatur batasan waktu secara berbeda-beda, sehingga sulit untuk merujuk pada undang-undang tersebut, terlebih ancaman ekonomi belum diatur dalam empat undangundang tersebut. Oleh sebab itu, untuk menata batasan waktu pemerintah merespon ancaman ekonomi, maka perlu mengatur batasan waktu Presiden dalam memberlakukan keadaan bahaya. Merujuk pada format penilaian pertumbuhan ekonomi yang biasa dilakukan berdasarkan periode kuartal, maka batasan waktu yang dapat diterapkan adalah enam bulan dan dapat diperpanjang selama enam bulan. Pembatasan waktu selama enam bulan dilakukan agar pemerintah memiliki waktu cukup untuk menilai kebijakannya berdampak atau tidak untuk mengatasi ancaman ekonomi, kemudian, perpanjangan waktu selama enam bulan dilakukan agar pemerintah dapat mengoreksi kebijakan pada semester kedua untuk melanjutkan atau memperbaiki kebijakan sebelumnya. Pembatasan tersebut perlu dilakukan untuk memberikan kepastian pada pihak terdampak ancaman ekonomi.

Keempat, pertanggungjawaban kekuasaan dalam merespon ancaman ekonomi. Perppu 4/2008 dan Perppu 1/2020 (UU 2/2020) mengatur bahwa terhadap pelaksana kebijakan tidak dapat dihukum, dituntut pidana, perdata maupun tata usaha negara sepanjang kebijakan yang dilakukan berkaitan dengan perppu. Pengaturan tersebut menimbulkan masalah karena diatur dalam Perppu yang sifatnya seperti undang-undang. Jika perppu tidak ditolak atau diganti, maka ketentuan tersebut tetap berlaku. Hal ini menjadi alasan Penulis tidak sependapat untuk mengatur kebijakan dalam keadaan

\footnotetext{
32 Carmelo Ferlito, "Economic Policies in Times of Emergency", The Malaysian Reserve, edisi 26 Maret 2020, hlm. 12
} 
bahaya dengan perppu karena potensi penyimpangan dan format pertanggungjawaban susah dilakukan. Terkait pertanggungjawaban, Presiden selama menetapkan keadaan bahaya tidak dapat diintervensi, termasuk pelaksana kebijakan. Namun, setelah keadaan bahaya berakhir, baik Presiden maupun organ pelaksana dapat dituntut pertanggungjawaban terhadap praktik kebijakan yang telah dilakukan selama keadaan bahaya. Jika terdapat penyimpangan atau pelanggaran kebijakan selama pemberlakukan keadaan bahaya, maka Presiden dan organ pelaksana harus bertanggungjawab atas kebijakan tersebut baik pertanggungjawaban politis maupun pertanggungjawaban hukum, sehingga kekebalan (imunitas) hukum hanya berlaku sepanjang keadaan bahaya diberlakukan. ${ }^{33}$

\section{PENUTUP}

Pengaturan ancaman ekonomi sebagai ancaman keadaan bahaya memberikan kesempatan pada Presiden untuk membentuk kebijakan penting tanpa harus dibatasi oleh ketentuan peraturan lainnya yang justru menghambat proses penanggulangan ancaman ekonomi. Tidak diaturnya ancaman ekonomi sebagai bagian dari keadaan bahaya menyebabkan beberapa masalah seperti; Pertama, pembatasan terhadap kebijakan Presiden dalam merespon ancaman seperti yang dilakukan melalui Perppu 1/2020 (UU 2/2020) di mana kebijakan tersebut banyak dikritik bahkan sampai diuji materi pada Mahkamah Konstitusi. Hal tersebut terjadi karena Presiden membentuk kebijakan khusus namun tidak dilakukan dalam ranah hukum tata negara darurat, sehingga masyarakat menggolongkan kebijakan tersebut sebagai produk hukum biasa yang tunduk pada pembatasan dan tidak boleh melanggar ketentuan perundang-undangan. Kedua,

Kedua, ancaman ekonomi dapat melahirkan dampak yang besar termasuk pada aspek sosial, hukum dan politik seperti yang terjadi Tahun 1998 di mana krisis ekonomi mengakhiri kekuasaan orde baru dan menciptakan ketidakstabilan ekonomi. Dengan menjadikan ancaman ekonomi sebagai bagian keadaan bahaya, maka Indonesia memiliki sistem preventif yang mampu merespon dengan cepat ancaman ekonomi dan menekan dampak ancaman terhadap keamanan negara.

Kedua masalah diatas menunjukkan pentingnya untuk menata ancaman ekonomi dan praktik kekuasaan pemerintah dalam merespon ancaman ekonomi dalam rezim keadaan bahaya, sehingga memudahkan Presiden dalam membentuk kebijakan khusus untuk merespon ancaman ekonomi serta memulihkan kondisi ekonomi secara cepat tanpa dibatasi oleh ketentuan aturan yang berlaku dalam keadaan normal.

\section{DAFTAR PUSTAKA}

\section{Buku}

Ajey Lele, "Natural disasters: A nonmilitary threat to national security" dalam Chatterji, M. and Jain, B.M.(ed), Conflict and Peace in South Asia: Contributions to Conflict

\footnotetext{
33 Joshua L. Friedman, "Emergency Powers of The Executive: The President's Authority When All Hell Breaks Loose", Journal of Law and Health, Volume 25, No. 2, 2012, hlm. 265-306.
} 
Management, Peace Economics and Development, Vol. 5, Bingley: Emerald Group Publishing Limited, 2008.

Alan S Milward, War, Economy and Society, 1939-1945, Los Angeles: University of California Press, 1979.

Badan Pusat Statistik, Laporan Perekonomian Indonesia 2020, Jakarta: BPS RI, 2020.

Hal Hill, The Indonesian Economy in Crisis, Causes, Consequences, and Lessons, Singapura: Institute of Southeast Asian Studies, 1999.

Hendrawan Supratikno, Ekonomi Nurani VS Ekonomi Naluri, Jakarta: Yayasan Pustaka Obor Indonesia, 2011.

Kabul Arifin, et.al, Pokok-Pokok Pengertian dan Beberapa Persoalan Tentang S.O.B. Jakarta: Penerangan Angkatan Darat, 1957.

Oren Gross, Fionnuala Ni Aolain, Law in Times of Crisis: Emergency Powers in Theory and Practice, Cambridge: Cambridge University Press, 2006.

Saafroedin Bahar et. al, Risalah Sidang Badan Penyelidik Usaha-usaha Persiapan Kemerdekaan Indonesia (BPUPKI) Panitia Persiapan Kemerdekaan Indonesia (PPKI), Jakarta: Sekretariat Negara Republik Indonesia, 1993.

Scott M. Matheson, Presidential Constitutionalism in Perilous Times, Cambridge: Harvard University Press, 2009.

Stephen Morton, States of Emergency: Colonialism, Literature and Law, Liverpool: Liverpool University Press, 2013.

Todd A. Knoop, Recessions and Depressions: Understanding Business Cycles, Westport: Praeger Publisher, 2004.

William H. Kaempfer dan Anton D. Lowenberg, "Chapter 27: The Political Economy of Economic Sanctions" dalam Todd Sandler dan Keith Hartley, Handbook of Defense Economics, Volume 2, Amsterdam: North-Holland Publishing, 2007.

\section{Jurnal}

Agus Adhari, "Ambiguitas Pengaturan Keadaan Bahaya dalam Sistem Ketatanegaraan Indonesia”, Dialogia Iuridica: Jurnal Hukum Bisnis dan Investasi, Volume 11, No. $1,2019$.

Andrew Norris, "Sovereignty, Exception, and Norm", Journal of Law and Society, Volume 34, No. 1, 2007.

Jamal Ibrahim Haidar, "Sanctions and Export Deflection: Evidence from Iran", Journal Economic Policy, Volume 32, No. 90, 2017.

John Armitage, "State of Emergency: An Introduction" Journal Theory, Culture \& Society Volume 19 No. 4, 2001.

Joshua L. Friedman, "Emergency Powers of The Executive: The President's Authority When All Hell Breaks Loose", Journal of Law and Health, Volume 25, No. 2, 2012.

Joshua S. Hanan dan Catherine Chaput, "Stating the Exception: Rhetoric and Neoliberal Governance During the Creation and Passage of the Emergency Economic 
Dialogia luridica: Jurnal Hukum Bisnis dan Investasi

Volume 12 Nomor 1, November 2020

Stabilization Act of 2008", Journal of Argumentation and Advocacy, Volume 50, No. 1, 2013.

Mark Neocleous, "The Problem with Normality: Taking Exception to "Permanent Emergency", Journal of Alternatives Global, Local, Political, Volume 31, No. 2, 2006.

Patrick Thronson, "Toward Comprehensive Reform of America's Emergency Law Regime", Michigan Journal of Law Reform, Volume 46, No. 2, 2013.

Richard H. Ullman, "Redefining Security", Journal of International Security, Volume 8, No. 1, 1983.

Saul Eslake, "The Difference between a Recession and a Depression", Economic Papers A Journal of Applied Economics and Policy, Volume 28, No. 2, 2009.

Siamack Shojai dan Patricia S. Root, "Effectiveness Of Economic Sanctions: Empirical Research Revisited", International Business \& Economics Research Journal, Volume 12, No. 11, 2013.

Vedi R. Hadiz, "Retrieving the Past for the Future? Indonesia and the New Order Legacy”, Southeast Asian Journal of Social Science, Volume 28, No. 2, 2000.

\section{Makalah}

Anna Khakee, Securing Democracy? A Comparative Analysis of Emergency Powers in Europe, Policy Paper No. 30, Jenewa: Geneva Centre for the Democratic Control of Armed Forces (DCAF), 2009.

Christopher A. Casey, et al, The International Emergency Economic Powers Act: Origins, Evolution, and Use, Washington: Congressional Research Service, 2020.

William E. Scheuerman, "The Economic State of Emergency" makalah dipresentasikan pada International Conference on Carl Schmitt, diselenggarakan oleh Columbia University, Cardozo Law School, New School, New York, pada 23-25 April 1999.

\section{Artikel}

Carmelo Ferlito, "Economic Policies in Times of Emergency", The Malaysian Reserve edisi 26 Maret 2020.

Muhumed Mohamed Muhumed, "The Effect of Financial Crisis on International Security”, diakses pada https://www.researchgate.net/publication/311867747 pada tanggal 6 Oktober 2020 pukul 21.05.

\section{Peraturan Perundang-Undangan}

Undang-Undang Dasar Negera Republik Indonesia 1945

Konstitusi Prancis 1958

Konstitusi Filipina 1987

Peraturan Pemerintah Pengganti Undang-Undang Nomor 23 Tahun 1959 tentang Keadaan Bahaya

Undang-Undang Nomor 24 Tahun 2007 tentang Bencana Nasional 
Dialogia luridica: Jurnal Hukum Bisnis dan Investasi

Volume 12 Nomor 1, November 2020

Peraturan Pemerintah Pengganti Undang-Undang Nomor 4 Tahun 2008 tentang Jaminan Pengaman Sistem Keuangan

Undang-Undang Nomor 7 Tahun 2012 tentang Penanganan Konflik Sosial

Undang-Undang Nomor 6 Tahun 2018 tentang Karantina Kesehatan

Peraturan Pemerintah Pengganti Undang-Undang Nomor 1 Tahun 2020 tentang Kebijakan Keuangan Negara dan Stabilitas Sistem Keuangan untuk Penanganan Pandemi Corona Virus Disease 2019 (Covid- 19) dan/atau dalam Rangka Menghadapi Ancaman yang Membahayakan Perekonomian Nasional dan/atau Stabilitas Sistem Keuangan

National Emergency Act 1976

International Emergency Economic Powers Act (IEEPA) Tahun 1977

Emergency Economic Stabilization Act (EESA) 2008

\section{Putusan Pengadilan}

Putusan Mahkamah Konstitusi Nomor 138/PUU-VII/2009. 